\title{
ANDRAGOGIA: CONSIDERAÇÕES SOBRE A APRENDIZAGEM DO ADULTO
}

\section{ANDRAGOGY: CONSIDERATIONS ABOUT ADULT LEARNING}

\author{
Jair Antonio de Carvalho ${ }^{1}$, Marlene Pedrote de Carvalho ${ }^{2}$, Maria Auxiliadora Motta \\ Barreto $^{3}$ e Fábio Aguiar Alves ${ }^{4}$ \\ ${ }^{1,3}$ UniFOA - Centro Universitário de Volta Redonda \\ ${ }^{2}$ UBM - Centro Universitário de Barra Mansa \\ ${ }^{4}$ UFF - Pólo Universitário de Nova Friburgo
}

\section{Resumo}

No começo do século VII, tiveram início na Europa, as escolas para o ensino de crianças, dando origem à pedagogia, dos quais, pressupostos são utilizados até hoje para fundamentar a educação independente da idade. As crianças são dependentes, necessitam de cuidados de terceiros; na adolescência iniciam-se os questionamentos, na idade adulta acumulam-se as experiências, aprendem com os próprios erros, tendo-se a consciência do que ainda é preciso aprender. A andragogia significa ensino de adultos. No modelo andragógico a educação é de responsabilidade compartilhada entre professor e aluno. O professor deve aprender que os adultos preferem que ele lhes ajude a compreender a importância prática do assunto a ser estudado, preferem experimentar a sensação de que cada conhecimento fará diferença em suas vidas, mudará efetivamente suas vidas. É de fundamental importância enfatizar o modelo andragógico nas universidades e instituições de ensino para maior eficiência educacional.

Palavras-chave: Educação; Andragogia; Aprendizagem de adultos; Aprender-fazendo.

\begin{abstract}
During the beginning of Century VII, there were initiated in Europe, children's schools to teach, with the off spring to pedagogy, from where ideas have been used until nowadays, regardless of age. Children are dependants, need third part special care; during the teenager ship, they start their questioning. The adults accumulate experiences and learn with mistakes, learning how to do something by themselves, showing the consciousness of what is still to learn. The andragogy means, adult learning. However, in the andragogic model, the responsibility of education is shared between teacher and student. The teacher should know that adults prefer the practical relevance of the subject studied. They prefer to try the sensation of each knowledge will make an effective change in their lives. Hitherto, it is very relevant to emphasize the andragogic within universities and learning institutions in order to improve the education efficiency among different groups.
\end{abstract}

Key words: Education; Andragogy: Adult learning; do it and learn. 


\section{INTRODUÇÃO}

O presente trabalho é uma investigação bibliográfica enriquecida ou acrescida de reflexões desenvolvidas durante um curso de mestrado, acerca da aprendizagem de adultos e suas experiências previamente adquiridas - Andragogia.

Segundo Tardif (2000), tanto em suas bases teóricas quanto em suas conseqüências práticas, os conhecimentos profissionais são evolutivos e progressivos e necessitam, por conseguinte, de uma formação contínua. Os profissionais devem, assim, autoformar-se e reciclar-se através de diferentes meios, após seus estudos universitários iniciais. Desse ponto de vista, a formação profissional ocupa, em princípio, uma boa parte da carreira e os conhecimentos profissionais partilham com os conhecimentos científicos e técnicos, a propriedade de serem revisáveis, criticáveis e passíveis de aperfeiçoamento.

Da mesma forma, Freire (1980) relata que a educação crítica considera os homens como seres em desenvolvimento, como seres inacabados, incompletos em uma realidade igualmente inacabada. Os homens têm consciência de que são incompletos, e assim, nesse estar inacabados e na consciência que disso têm, encontram-se as raízes da educação como fenômeno puramente humano. O caráter inacabado dos homens e o caráter evolutivo da realidade exigem que a educação seja uma atividade contínua. A educação é, deste modo, referida pela práxis. Dessa forma, concordamos com Busato (2005) quando afirma que encontrar alternativas ou até mesmo ressignificá-las e construí-las com base no contexto concreto de vivência da prática pedagógica, demanda apropriação, elaboração de saberes, de fundamentos teórico-práticos.

Sendo o homem um ser social, é interessante a observação de Chassot (2006) quando comenta que as informações são importantes para a prática da cidadania, mas que devem ser transmitidas numa linguagem mais acessível, criando condições de entendê-las, sendo assim um instrumento de leitura da realidade e facilitadora da aquisição de uma visão crítica, o que guarda similaridade ao exposto por Moreira (2005), quando diz que, para que haja o aprendizado, é necessário que as informações estejam conforme a necessidade da pessoa, sua vivência e seu cotidiano.

Rodrigues (2001), diz que educar é acionar os meios intelectuais do educando para que seja capaz de assumir o pleno uso de suas potencialidades físicas, intelectuais e morais. Esta é uma das condições para que ele se construa como sujeito livre e independente daqueles que o estão gerando como ser humano. 
Na mesma linha de pensamento, o alerta de Leitão (2004) é muito importante para nossas considerações, quando destaca, que apesar de todos os avanços em torno das concepções de educação - apoiados, sobretudo, no desenvolvimento das ciências humanas, o que observamos é que nem sempre essas referências trazem modificações substanciais às práticas, não garantem uma relação efetiva, um melhor desempenho no aprendizado ou uma prática mais democrática, se os professores não estiverem sensibilizados e sentirem necessidade de participar dessa mudança.

Assim, este trabalho tem como objetivo, oportunizar reflexão sobre a andragogia, visando contribuir para a melhoria do ensino para adultos, respeitando e aproveitando os conhecimentos prévios adquiridos ao longo da vida do sujeito, a fim de valorizar o aprendizando, transformando o aprendiz de objeto a sujeito da educação, justificando-se pela necessidade de trazer à tona, novas discussões sobre a educação, dentro dos princípios andragógicos.

\section{DESENVOLVIMENTO}

Os diversos estudos sobre a infância e a experiência com crianças denotam que as mesmas são seres dependentes, necessitam dos cuidados de terceiros, acostumam-se a esta dependência que é aceita, por todos, como normal. Nessa fase, quando se inicia o período escolar, é esperada proteção por parte dos professores. Já na adolescência iniciam-se os questionamentos, aparecem às rebeldias e a autoridade dos professores deixa de ser absoluta. Na idade adulta acumulam-se experiências, aprende-se com erros, tendo consciência do que não se sabe e quanto estes desconhecimentos fazem falta. Os adultos avaliam cada informação que lhes chega e a incorporam ou não, em função de suas necessidades.

Num breve levantamento histórico do ensino, pode-se constatar que no começo do século VII, foram iniciadas na Europa escolas para o ensino de crianças, cujo objetivo era preparar jovens rapazes para o serviço religioso (OLIVEIRA, 2007). Eram as conhecidas Catedrais ou Escolas Monásticas. Os professores dessas escolas tinham como missão a doutrinação dos jovens na crença, fé e rituais da Igreja. Eles reuniram uma série de pressupostos sobre aprendizagem, ao que denominaram de "pedagogia. A palavra, literalmente, significa "a arte e ciência de ensinar crianças" - a etimologia da palavra é grega: "paido", que significa criança, e "gogos" que significa educar. Esse modelo de educação monástico foi mantido, através dos tempos, até o século XX, por 
não haver estudos aprofundados de sua inadequação para outras faixas etárias, que não a infantil. Veio, assim, a ser a base organizacional de todo o nosso sistema educacional, incluindo o empresarial. Entretanto, logo após a Primeira Guerra Mundial, começou a crescer nos Estados Unidos e na Europa um corpo de concepções diferenciadas sobre as características do aprendiz adulto que, infelizmente, ainda não é considerado por completo na educação de quem não é mais criança.

Este processo é, ainda hoje, ignorado pelos sistemas tradicionais de ensino e na maioria dos casos, tenta-se ensinar adultos com as mesmas técnicas didáticas usadas no ensino fundamental e médio. Segundo Cavalcanti (1999), apenas em 1926, Linderman, na tentativa de buscar melhores formas de educar adultos, percebeu a falta de adequação dos métodos utilizados e escreveu: "nós aprendemos aquilo que nós fazemos. A experiência é o livro-texto vivo do adulto aprendiz". Knowles, em 1970, trouxe à tona as idéias de Linderman e introduziu em 1973 o termo andragogia (do grego: andros = adulto e gogos = educar), como "a arte e a ciência de ajudar adultos a aprender". Bellan (2005) destaca que andragogia é a ciência que estuda como os adultos aprendem, e quem primeiro usou esta nomenclatura foi o educador alemão Alexander Kapp, em 1833 para descrever elementos da teoria de Educação de Platão.

Seguindo esta linha de pensamento, Perissé (2008) relata que o estudante adulto não pode ser tratado pelos professores como se fosse um adolescente e estivesse apenas começando a entrar no labirinto da vida. Os professores devem ser capazes de compreender que este aluno (com mais idade do que eles, às vezes) requer desafios. Mais do que ficar ouvindo, passivamente, a exposição muitas vezes abstrata e tediosa de um assunto, precisa gerir seu aprendizado e seu desenvolvimento profissional. $\mathrm{O}$ professor deve aprender que os adultos precisam que ele lhes ajude a compreender a importância prática do assunto a ser estudado, experimentar a sensação de que cada conhecimento fará diferença e mudará efetivamente suas vidas.

Pinto (2007) relata que a educação formalizada é um dos processos pelos quais a sociedade se configura, mas não o é, como retrata a pedagogia ingênua, aquela que parte de idéias pré-concebidas sobre a realidade e que não leva em consideração o sujeito real. Todos os processos configuradores da sociedade estão em estreita relação recíproca e se influenciam mutuamente. Logo, a educação só alcança os resultados que o conjunto dos demais processos lhes permite obter. 
Segundo Hamze (2008) a andragogia é um caminho educacional que busca compreender o adulto, podendo ser considerada uma teoria, mas também um método de ensino, que se reflete em um somatório de trocas de conhecimentos entre o facilitador do conhecimento e o estudante adulto e suas experiências de vida.

No modelo andragógico, a aprendizagem é de responsabilidade compartilhada entre professor e aluno. A andragogia fundamenta-se no "aprender fazendo".

Segundo Finger (2003), a educação de adultos tem merecido especial atenção da UNESCO (Organização das Nações Unidas para a Educação, a Ciência e a Cultura), desde a sua criação, podendo a sua contribuição para este campo ser considerada histórica, especialmente no que se refere à alfabetização e educação básica de adultos.

Em continuidade a essa atenção, Pinto (2007), afirma ainda que o método é de fundamental importância no processo de educação do adulto, por se tratar de pessoa já dotada de uma consciência formada, com hábitos de vida e situações de trabalho que não podem ser arbitrariamente modificados. As características que devem fundamentar este método são as seguintes:

- Despertar no adulto a consciência da necessidade de instruir-se e a noção clara da sua participação na sociedade;

- Partir dos elementos que compõem a realidade do educando, que se destacam como expressão de sua relação direta e contínua com o mundo em que vive;

- Não impor o método ao educando e, sim, criá-lo com ele, com base na realidade em que vive. O professor instrutor deve atuar como incentivador da busca autônoma de conhecimentos.

- Propor o conteúdo da instrução, o que deve ser justificado como uma contribuição para melhorar as condições de vida do homem.

Danyluk (2001) relata que o adulto escolarizado é um sujeito culto, no sentido objetivo da cultura, porque consegue sobreviver na sociedade na qual está inserido. Aquilo que desconhece, talvez seja o que até então, não teve necessidade ou oportunidade de aprender. As pessoas que não sabem ler nem escrever, já atuam em seus mundos como educados, ainda que não de forma escolarizada. O adulto traz consigo os saberes de suas vivências, embora dúvidas e medos o acompanhem, e deixam à vista um ser cheio de vida e experiência existencial. 
Para DeAquino (2007), a andragogia apresenta-se atualmente, como uma alternativa à pedagogia clássica e refere-se à educação centrada no aprendiz, para jovens e adultos.

Ainda segundo Perissé (2008), os conceitos andragógicos devem ser aplicados na formação do professor, uma vez que é adulto e necessita ver e tratar seus alunos adultos como pessoas verdadeiramente livres e responsáveis. Esta é a motivação das motivações - ser tratado como um ser inteligente, capaz de acertar na vida. Muito além das notas, os alunos maduros anseiam ver como a realidade acadêmica concorrerá de fato para que sua realidade pessoal seja dinâmica, produtiva. Os professores de alunos adultos, pressionados por problemas que a pedagogia só em parte pode solucionar, precisam estudar Andragogia. $\mathrm{O}$ adulto aprendiz é quem melhor ensinará como ensinar.

Hamze (2008), relata ainda que na Andragogia a aprendizagem tem uma particularidade mais centrada no aluno, na independência e na auto-gestão da aprendizagem, para a aplicação prática na vida diária.

Sobre a discussão acerca da pedagogia e da andragogia na educação de jovens e adultos, podemos considerar o que aponta DeAquino (2007 p. 13).

A grande discussão hoje existente nos meios universitários e de educação continuada é se a pedagogia é uma forma adequada para o ensino e aprendizagem de adultos ou se a andragogia, uma abordagem que considera a postura crítica e a necessidade da experimentação, seria capaz de trazer resultados melhores para esse grupo particular de aprendizes.

Nosso entendimento é de que existe um contínuo, no qual a pedagogia, também conhecida com aprendizagem direcionada, posiciona-se em uma extremidade, enquanto a andragogia (aprendizagem facilitada) encontra-se em outra. De modo a se ter eficácia e eficiência no processo de aprendizagem, é necessário que professores e organizações educacionais sejam capazes de se mover ao longo desse intervalo e encontrar a combinação correta entre as duas abordagens.

Concordamos com as colocações acima e completamos com o que Chotguis (2007) relata, acerca do desenvolvimento das teorias de educação. Apenas em 1950, alguns educadores começaram a organizar idéias em torno da noção de que adultos aprendem melhor em ambientes informais, confortáveis, flexíveis e não ameaçadores e o termo somente foi usado nos anos 60 .

A andragogia foi apresentada como a arte e a ciência de ajudar o adulto a aprender e era ostensivamente a antítese do modelo pedagógico clássico que significa, 
literalmente, a arte e ciência de ensinar crianças. Esse modelo pedagógico, aplicado também ao aprendiz adulto, persistiu através dos tempos chegando até o século presente e foi a base da organização do nosso atual sistema educacional. Confere ao professor responsabilidade total para tomar todas as decisões a respeito do que vai ser aprendido, como será aprendido, quando será aprendido e se foi aprendido. É um modelo centrado no professor, deixando ao aprendiz somente o papel submisso de seguir as instruções do professor.

Segundo DeAquino (2007), a andragogia, inicialmente definida como a arte de ajudar os adultos a aprender, apresenta-se atualmente como uma alternativa à pedagogia e refere-se à educação centrada no aprendiz para pessoas de todas as idades.

Sabemos que à medida que as pessoas amadurecem, sofrem transformações como: passar de dependentes para indivíduos independentes (autodirecionados); acumular experiências de vida que vão fundamentar o substrato de seu aprendizado; direcionar seus interesses para o desenvolvimento das habilidades que utiliza em seu papel social; esperar uma imediata aplicação prática do que aprendem; preferir aprender para resolver problemas e desafios e passar a apresentar motivações internas mais intensas do que motivações externas (Knowles, 2005).

Dessa forma, a andragogia é descrita mais como uma forma seqüencial do modo de aprender do que como uma teoria (KAUFMANN, 2000),. Ela oferece, quando muito, as diretrizes de aprendizagem para pessoas que tenham tendência à autonomia e à autoinstrução. São sete as hipóteses por ele levantadas:

1. É necessário um ambiente de aprendizagem eficaz. Os estudantes devem se sentir calmos do ponto de vista psíquico. Eles devem se sentir seguros para se exprimir sem se expor ao julgamento ácido ou ao ridículo.

2. Os estudantes devem participar da elaboração do programa de estudos que deve ser efetivo para o conteúdo e para o processo de aprendizagem.

3. Devem ser estimulados a participar na determinação de suas necessidades educativas o que favorece a auto-motivação, auto-avaliação e a reflexão.

4. Os estudantes devem fixar suas necessidades de aprendizagem, ou seja, a responsabilidade principal por seu aprendizado é deles próprios.

5. Deve-se incitá-los a identificar os recursos necessários para que atinjam os objetivos de aprendizado. Esse princípio estabelece a ligação entre as necessidades, os recursos e os objetivos finais da aprendizagem. 
6. Auxiliar os estudantes a colocar em prática seus projetos de aprendizagem. Um dos elementos-chave da motivação é a expectativa de alcançar um bom resultado. Quando muito cobrado, ele perde a motivação para estudar, aparecendo o mal resultado.

7. É necessário que os estudantes estejam implicados em seus próprios processos de avaliação. Essa é uma ferramenta fundamental ao processo de aprendizado autodirigido e que necessita de reflexão crítica.

Knowles (2005), afirma, ainda, que o comportamento do aprendiz varia de acordo com a aprendizagem e que situações da vida afetam também o estilo andragógico de aprendizagem. Experiências passadas e atuais também ajudam a formatar a aprendizagem, sendo que adultos aprendem mais no contexto da vida real, sendo motivados em aprender para solucionar problemas. Durante anos se refinou o modelo andragógico emergente, o que, em nossa opinião, fortificaram-no. Aprender é um fenômeno complexo que desafia qualquer modelo.

Em contraposição ao modelo pedagógico, Chotguis (2007) relata que o modelo andragógico é baseado em vários outros pressupostos, dentre os quais destacamos:

1. A Necessidade de Saber. Os adultos investem energia investigando o que ganharão em aprender algo, assim, necessitam saber PORQUÊ aprender.

2. Autoconceito do Aprendiz. Os adultos respondem ao autoconceito de serem responsáveis pela própria vida e pelo que acontece com ela, inclusive pelo que aprende.

3. O Papel das Experiências dos Aprendizes. Os adultos acumulam mais experiências e de diferentes tipos, do que na juventude.

4. Prontos para Aprender. Adultos estão prontos para aprender o que vai fazer diferença em sua vida cotidiana, em situações reais.

5. Motivação. As pressões internas, como desejo de satisfação no trabalho e auto-estima são motivadores mais potentes para os adultos do que as externas, como melhor emprego, salário etc.

Knowles (2005), afirma que, ao se considerar uma teoria, deve-se entender as complexidades envolvidas na definição de educação e aprendizagem Educação enfatiza o educador enquanto a aprendizagem enfatiza a pessoa na qual ocorrerão mudanças. Embora esta definição seja facilmente compreensível, desenvolver uma definição de trabalho de aprendizagem é muito mais complexo. A teoria de aprendizagem refere-se a métodos de aprendizagem enquanto a de ensino refere-se a métodos empregados para se 
influenciar a aprendizagem, logo, entende-se a aprendizagem como processo de ganho de conhecimento e ou experiência.

Segundo Freire (1992) as relações do homem com o mundo, independem do fato de ser alfabetizado ou não, basta ser homem para realizá-las, para ser capaz de captar os dados da realidade, de saber, ainda que seja este saber meramente opinativo. Daí que não haja ignorância nem sabedoria absoluta. A compreensão resultante da captação será tão mais crítica, quanto seja feita a apreensão da causalidade autêntica. E será tão mais mágica, na medida em que se faça com um mínimo de apreensão dessa causalidade. Enquanto para a consciência crítica, a própria causalidade autêntica está sempre submetida a sua análise - o que é autêntico hoje pode não ser amanhã - para a consciência ingênua, o que lhe parece casualidade autêntica já não é, uma vez que lhe atribui caráter estático de algo já feito e estabelecido.

A consciência crítica é a representação das coisas e dos fatos como se dão na existência empírica. A consciência ingênua, pelo contrário, se crê superior aos fatos, dominando-os de fora e, por isso, se julga livre para entendê-los conforme melhor lhe agradar. A consciência mágica, não chega a acreditar-se superior aos fatos, dominandoos de fora, nem se julga livre para entendê-los como melhor lhe agradar. Por isso é próprio da consciência crítica a sua integração com a realidade, enquanto que da ingênua o próprio é sua superposição à realidade. Devemos buscar, na educação de adultos, o desenvolvimento da consciência crítica.

Bellan (2005) destaca que quando se olha a aprendizagem de adultos através da andragogia, vê-se que o papel do professor como é tradicionalmente conhecido, deve ser revisto. Porque os alunos adultos são conscientes de suas habilidades e experiências, e exigem mais envolvimento no processo de aprendizagem. $O$ professor deve transformar-se em facilitador, um agente de transformação. Sobre o conceito de facilitação, Finger (2003) destaca que está diretamente relacionada com o conceito de crescimento, chamada aprendizagem autodirigida.

Knowles (2005), afirma que a andragogia é o modelo certo numa dada situação de aprendizagem adulta e disse ainda, em 1989, que, preferia pensar na andragogia como modelo de conceitos que servem como base para uma teoria emergente.

A transição da pedagogia para a andragogia deve ser feita durante os estudos universitários, tendo em vista que a maioria dos graduandos inicia os estudos como adolescente e termina como adulto. Enfatizar a aplicação dos princípios andragógicos 
nas universidades é de fundamental importância, a fim de atingir maior eficiência educacional.

\section{CONCLUSÕES}

A andragogia, apesar de pouco conhecida, é uma ciência que vem provocando discussões ao longo do tempo: Galileu Galilei (1564-1642) já dizia. "não se pode ensinar coisa alguma a alguém, pode-se apenas auxiliá-lo a descobrir por si só". Kaufmann (2000), afirma que a andragogia oferece as diretrizes de aprendizagem para pessoas que tenham tendência à autonomia e a auto-instrução.

Com a utilização da palavra andragogia, ocorre uma situação semelhante ao que acontece com o termo "célula", que foi designado indevidamente por Robert Hoock em 1564, como unidade fundamental da matéria viva, uma vez que, sabe-se que célula vem de "cela", que quer dizer espaço vazio. No caso da andragogia, a palavra é desconhecida por muitos que usam o termo "pedagogia do adulto", indevidamente. Há de se ressaltar aqui, que em muitos casos, embora a palavra andragogia não apareça, grandes educadores usam implicitamente os princípios andragógicos.

Uma das formas de reverter este problema seria ignorar o termo "pedagogia do adulto" e passar a utilizar o termo andragogia, promovendo reflexão sobre o tema, através da produção de artigos, com o intuito de levar especialmente a comunidade científica a pensar sobre o caso, impedindo que aconteça com a andragogia como aconteceu com a palavra célula, que há quase 500 anos nada foi feito.

O estudo aqui desenvolvido, permite concluir que o ensino realizado sob o foco da andragogia será capaz de desenvolver nos adultos toda sua capacidade, permitindo assim que suas habilidades sejam devidamente afloradas, assim como a continuidade da utilização de métodos que já haviam sido considerados eficientes pelo próprio sujeito .

Nos adultos, a aprendizagem é orientada para a resolução de problemas e tarefas com que se confrontam na sua vida cotidiana, o que desaconselha uma lógica centrada nos conteúdos, uma vez que estão dispostos a iniciar um processo de aprendizagem desde que compreendam a sua utilidade.

Os adultos são sensíveis a estímulos de natureza externa, como, por exemplo, a atribuição de notas nos trabalhos desenvolvidos, mas são os fatores de ordem interna que os motivam para a aprendizagem: satisfação, auto-estima, qualidade de vida, entre outros. 
No contexto da andragogia, a aprendizagem adquire uma característica mais centrada no aluno, na independência e na auto-gestão da aprendizagem. Pessoas aprendem o que realmente precisam saber (aprendizagem para aplicação prática na vida diária), sendo a experiência uma rica fonte de aprendizagem, através da discussão e da solução de problemas em grupo.

O conteúdo da instrução deve ser proposto e não imposto e o projeto de aprendizagem voltado para as necessidades do aprendiz. O método deve despertar a necessidade de instruir-se, a fim de deixar clara a usa participação, como um cidadão integrado na sua sociedade partindo de elementos que compõem a realidade do aprendiz.

Quando se olha a aprendizagem de adultos através da andragogia, vê-se que o papel do professor como é tradicionalmente conhecido, deve ser revisto. Os alunos adultos são conscientes de suas habilidades e experiências, e exigem seu maior envolvimento no processo de aprendizagem. O professor deve transformar-se em facilitador, em agente de transformação.

A transição da pedagogia para a andragogia deve ser feita durante os estudos universitários, em função da faixa etária em que se encontram os jovens ingressantes na graduação, portanto, programar o ensino de adultos sob o foco da andragogia tanto nas universidades, como em outras instituições de ensino, trará grandes benefícios para o aprendiz, fazendo que se transformem em profissionais mais conscientes e capacitados. Este é o grande desafio da educação de adultos, pois a prática atual tem se mostrado insuficiente para atingir os objetivos propostos.

\section{REFERÊENCIA}

BELlAN, Z. S., Andragogia em Ação: Como ensinar adultos sem se tornar Maçante, Santa Bárbara d Oeste, SOCEP Editora, 2005.

BUSATO, Z. S. L., Avaliação nas práticas de ensino e estágios. A importância dos registros na reflexão sobre a ação docente, Porto Alegre: Mediação, 2005.

CAVAlCANTI, R.A., Andragogia: A aprendizagem nos adultos. Rev. De Clínica Cirúrgica da Paraíba, n.6, Ano 4, Jul. 1999.

CHASSOT, A., Alfabetização Científica: Questões e desafios para a educação, 4 ed. Editora Unijuí. Ijuí 2006. 
CHOTGUIS, J., Andragogia - Arte e ciência na aprendizagem do adulto - Disponível em www.serprofessoruniversitario.pro.br - Acessado em 14/04/2010.

DEAQUINO, T. C. E., Como Aprender: Andragogia e as habilidades de aprendizagem, São Paulo, Pearson Prentice Hall, 2007.

DANYLUK, S. O., Educação de Adultos. Ampliando horizontes de conhecimento, Porto Alegre, Editora Sulina, 2001.

FINGER, M., ASÚN, J. M., A Educação de Adultos numa Encruzilhada: Aprender a nossa saída, Porto - Portugal, Porto Editora, 2003.

FREIRE, P., Conscientização: Teoria e prática da libertação: uma introdução ao pensamento de Paulo Freire, 3. ed. São Paulo, Moraes, 1980.

Terra S/A, 1992.

Educação Como Prática da Liberdade, 21. ed., Rio de Janeiro, Paz e

HAMZE, A., Andragogia e a arte de ensinar aos adultos, Acessado em 14/04/2010. Disponível em http://www.educador.brasilescola.com/trabalho-docente/andragogia.htm

LEITÃO, C. F., Buscando caminhos nos processos de formação/automação. Rev. Brasileira de Educação, Rio de Janeiro, n.27, p.25-39, Set/Out/Nov/Dez. 2004.

KAUFMANN, D., Le nouveau Paradigme dans l'enseignement medical: Comment la théorie peut exercer une influence sur la pratique. Conferences Inaugurales.Université Dalhousie. Halifax. Canadá. 2000.

Disponível em www.cidmed.u-bordeaux2.fr/wnantes/text2.htm.

KNOWLES, M. S., The Adult Learner: The Definitive Classic in Adult Education and Human Resource Development, 6th ed. San Diego, Califórnia, USA, Elsevier, 2005.

MOREIRA I. C. et al. Terra Incógnita: A interface entre ciência e público, Editora Vieira Lent. Rio de Janeiro, 2005.

OLIVEIRA, A. B., Gestão Andragógica: Tornando a empresa Adulta, Belo Horizonte, UNA, 1999.

PERISSÉ, G., Andragogia - Disponível em www.correiocidadania.com.br - Acessado em 14/04/2010.

PINTO, A. V., Sete Lições Sobre Educação de Adultos, 15 ed. São Paulo, Cortez Editora, 2007.

RODRIGUES, N., Educação: da formação humana a construção do sujeito ético, Rev. Educação \& Sociedade, ano XXII, n 76, Outubro/2001.

TARDIF, M., Saberes profissionais dos professores e conhecimentos universitários, Elementos para uma epistemologia da prática profissional dos professores e suas 
conseqüiências em relação à formação para o magistério, Rev. Brasileira de Educação, Rio de Janeiro, n.13, p.655-676. Jan/Fev/Mar/Abr. 2000. 